\title{
Nucleotídeos na dieta de frangos de corte e seus efeitos sobre taxa de turnover da mucosa intestinal antes e após lesões causadas por coccidiose
}

\author{
Nucleotides in broilers challenged diet and its effects on intestinal mucosa turnover rate before and \\ after injuries caused by coccidiose
}

\author{
Vanessa Cristina Pelícia ${ }^{\mathrm{I}}$ Kelen Cristiane Zavarize $^{\mathrm{I}}$ Carlos Ducatti $^{\mathrm{II}}$ Ana Cristina Stradiotti ${ }^{\mathrm{I}}$ \\ Antonio Celso Pezzato ${ }^{I}$ Priscila Cavalca de Araujo ${ }^{I}$ Mariela Akie Okino Mituo ${ }^{I}$ \\ Luciene Aparecida Madeira ${ }^{I}$ José Roberto Sartori $^{\mathrm{I}}$
}

\section{RESUMO}

O objetivo deste trabalho foi avaliar o efeito da dieta suplementada com nucleotídeos sobre taxa de turnover da mucosa intestinal de frangos antes e após lesões causadas por coccidiose por meio de análise isotópica, utilizando a variação do carbono-13 em plantas $C_{3}$ e $C_{4}$. Foram utilizados 264 pintos submetidos a dois tratamentos: dieta controle $e$ dieta suplementada com 0,07\% nucleotídeos. Os pintos possuíam sinais isotópicos em seus tecidos semelhantes ao de ditas $C_{4}$. Após o alojamento, para avaliar taxa de turnover da mucosa, as aves receberam dietas predominantemente $C_{3}$. Com 16 dias de idade, 50\% das aves de cada tratamento foram inoculadas com oocistos de Eimeria acervulina e, a partir de 21 dias, para avaliar a taxa de turnover após desafio, as aves passaram a receber dieta predominantemente $\mathrm{C}_{4}$. Amostras de mucosa foram analisadas isotopicamente por espectrometria de massa. Na fase inicial, a suplementação com nucleotídeos propiciou aceleração na troca do carbono na mucosa, com meia-vida de 1,06 e 1,01 dias para dieta controle e com nucleotídeos, respectivamente, acelerando o crescimento intestinal. Na fase de 21 a 42 dias de idade, para os grupos não desafiados com coccidiose, as meias-vidas do carbono foram 1,81 e 1,80 dias para dieta controle e com nucleotídeos, respectivamente, não havendo influência dos tratamentos. Porém, nos grupos desafiados, as meias-vidas foram 1,01 dias no grupo controle e 0,75 dias no que recebeu dieta com nucleotídeos, indicando maior turnover da mucosa nesse último grupo. A adição de nucleotídeos promove aceleração no processo de renovação da mucosa intestinal e na regeneração após danos causados por coccidiose.

Palavras-chave: Eimeria acervulina, Carbono-13, isótopos estáveis, regeneração.

\section{ABSTRACT}

The objective was to evaluate the effect of nucleotides supplementation diet on the intestinal mucosa turnover rate of broilers before and after injury caused by coccidiosis, through isotopic analysis, using the carbon-13 variation in $C^{3}$ and $C^{4}$ plants. It was used 264 chicks under two treatments: control diet and diet supplemented with $0.07 \%$ nucleotides. The chicks had isotopic signals in their tissues similar to $C_{4}$ diet. After housing, to assess mucosal turnover rate, the birds were fed with a predominantly $C_{3}$ diet. At 16 days of age, 50\% of birds from each treatment were inoculated with Eimeria acervulina oocysts and starting from 21 days, to assess the mucosa turnover rate after challenge, the birds received predominantly $\mathrm{C}_{4}$ diet. Samples of intestinal mucosa were isotopically analyzed by mass spectrometry. In the initial phase, supplementation with nucleotides led acceleration in carbon trading in the mucosa, with half-lives of 1.06 and 1.01 days for control diet and with nucleotides, respectively, accelerating intestinal growth. During the 21 to 42 days of age, for not coccidiosis challenged groups, the carbon half-lives were 1.81 and 1.80 days for control diet and with nucleotides respectively, without any influence of the treatments. However, in the challenged groups, the half-lives were 1.01 days in control group and 0.75 days in group receiving nucleotides diet supplementetion, indicating a higher mucosa turnover rate in the latter group. The addition of nucleotides promotes acceleration in the cell renewal process of intestinal mucosa and in regeneration after damage caused by coccidiosis.

Key words: Eimeria acervulina, Carbon-13, regeneration, stable isotopes.

'Faculdade de Medicina Veterinária e Zootecnia (FMVZ), Universidade Estadual Paulista (UNESP), 18618-000,Botucatu, SP, Brasil. E-mail: vcpelicia@yahoo.com.br.*Autor para correspondência.

IIInstituto de Biociências (IBB), Universidade Estadual Paulista (UNESP), Botucatu, SP, Brasil. 


\section{INTRODUÇÃO}

Recentemente, tem crescido a preocupação dos consumidores em relação ao uso de antibióticos melhoradores de desempenho e anticoccidianos na alimentação animal, bem como com a qualidade dos produtos, exigindo alimentos mais saudáveis com ausência de resíduos químicos. Diante dessa situação e para evitar quedas de desempenho na produção avícola, nutricionistas trabalham em uma série de produtos e/ou nutrientes alternativos que auxiliam, por meio de mecanismos específicos, a superar desafios que favorecem a manifestação de problemas entéricos nos animais.

Estudos têm demonstrado que os nucleotídeos da dieta são capazes de melhorar a resposta imune (YAMAUCHI et al., 1996), promover o aumento da altura das vilosidades intestinais com consequente aumento da absorção dos nutrientes (YU et al., 2002) e prevenir os efeitos negativos sobre a estrutura do intestino (ADJEI et al., 1996), evitandose, assim, quedas de desempenho.

Segundo BUENO et al. (1994), a suplementação com nucleotídeos é especialmente importante no desenvolvimento de tecidos com rápido turnover celular, quando a capacidade de síntese endógena não é suficiente para responder às maiores exigências, como em períodos de rápido crescimento e após agressões no organismo, tais como doenças ou traumas.

A diferença natural na razão isotópica de carbono $\left({ }^{13} \mathrm{C} /{ }^{12} \mathrm{C}\right)$ existente entre as plantas de ciclo fotossintético distinto $\left(\mathrm{C}_{3} \mathrm{e}_{4}\right)$ oferece a possibilidade de utilizá-las como marcadores nos tecidos animais, sem a necessidade de sintetizar compostos especificamente marcados, evitando problemas de saúde humana e de segurança ambiental, associados ao uso de isótopos radiativos (METGES et al., 1990). Esses marcadores vêm sendo utilizados com eficácia em estudos com suínos (CALDARA et al., 2010), aves (CRUZ et al., 2005; GOTTMANN et al., 2008), entre outras espécies. Segundo GANNES et al. (1998), dietas com assinaturas isotópicas distintas podem ser utilizadas para mensurar o turnover de componentes corporais e órgãos de animais.

Desse modo, com o presente trabalho, objetivou-se avaliar o efeito da suplementação da dieta com nucleotídeos sobre a taxa de turnover do carbono da mucosa intestinal de frangos de corte submetidos ou não ao desafio por coccidiose e, consequentemente, seu processo de renovação, utilizando-se a variação natural do carbono-13, existente entre as plantas de ciclo fotossintético distinto.

\section{MATERIAL E MÉTODOS}

O experimento foi conduzido na Faculdade de Medicina Veterinária e Zootecnia da UNESP, Campus de Botucatu, nas instalações do Laboratório de Nutrição de Aves. Foram utilizados 264 pintos de corte machos, da linhagem Hybro, com um dia de idade. Em câmara climática, com temperatura e ventilação controladas e mantidas na zona de conforto térmico, as aves foram alojadas em gaiolas de arame galvanizado, nas quais foram criadas até 42 dias de idade. $\mathrm{O}$ fornecimento de luz foi constante durante todo período de criação.

O período de criação foi dividido em apenas duas fases: inicial ( 1 a 21 dias de idade) e crescimento (22 a 42 dias de idade) para se obter menor variação nos sinais isotópicos das dietas. As exigências nutricionais das aves foram estabelecidas de acordo com as tabelas de exigências nutricionais de ROSTAGNO et al. (2005), adaptadas para as duas fases de criação. Os pintos de corte foram obtidos de matrizes que estavam recebendo dietas compostas predominantemente por plantas do ciclo fotossintético $\mathrm{C}_{4}$ (a base de milho e soja). Estes, ao nascerem, possuíam em seus tecidos corporais sinais isotópicos de ${ }^{13} \mathrm{C}$ semelhantes ao destas dietas $\left(\delta^{13} \mathrm{C}=-19,31 \%\right.$ o $)$. Após o alojamento, para avaliar a taxa de turnover na mucosa intestinal, os pintos de um dia de idade receberam dietas compostas predominantemente por plantas do ciclo $\mathrm{C}_{3}$ (a base de arroz e soja), possuindo sinal isotópico de ${ }^{13} \mathrm{C}\left(\delta^{13} \mathrm{C}=-27,95\right.$ e $-27,98 \%$ o) diferente das dietas $\mathrm{C}_{4}$ fornecidas às matrizes, provocando mudança no sinal isotópico de seus tecidos corporais. As aves foram distribuídas aleatoriamente em dois tratamentos iniciais: $\mathrm{T} 1=$ dieta controle sem adição de nucleotídeos e T2 = dieta suplementada com $0,07 \%$ de nucleotídeos (mistura em concentrações iguais de adenina, guanina, citosina e uracila - AccelerAid ${ }^{\circledR}$ ).

Aos $0 ; 0,5 ; 1 ; 1,5 ; 2 ; 2,5 ; 3 ; 3,5 ; 4 ; 4,5 ; 5 ; 7 ; 9$

e 14 dias de idade, foram retiradas aleatoriamente três aves por tratamento, sacrificadas por deslocamento da articulação crânio-cervical, das quais foram colhidas amostras de mucosa do intestino delgado (na altura da porção final da alça duodenal) por meio de raspagem com lamínula de vidro. As coletas foram concentradas nos primeiros dias de vida, devido à maior velocidade na diluição isotópica do ${ }^{13} \mathrm{C}$ nos tecidos durante essa fase (HOBSON \& CLARK, 1992). Cada ave retirada dos tratamentos foi considerada uma repetição. As amostras foram acondicionadas em frascos graduados de 1,0mL, identificadas e imediatamente congeladas a $18^{\circ} \mathrm{C}$ até a sua preparação para as análises isotópicas. 
Com 16 dias de idade, $50 \%$ das aves de cada tratamento foram transferidas para outra câmara climática e inoculadas oralmente e individualmente com auxílio de pipeta com 500.000 oocistos de Eimeria acervulina, causando de moderadas a fortes lesões no epitélio intestinal das aves, dose definida por WILLIAMS (2001). A transferência das aves para outra câmara teve por objetivo evitar contaminação do grupo não inoculado com os oocistos. A temperatura e ventilação foram controladas e mantidas na zona de conforto térmico igualmente nas duas câmaras climáticas. Como o ciclo da Eimeria acervulina é de quatro a cinco dias, ocorrendo ao final desse período as primeiras lesões no epitélio intestinal, aos 21 dias de idade, as aves passaram a receber dietas compostas predominantemente por plantas do ciclo $\mathrm{C}_{4}$ (a base de milho e soja), possuindo sinal isotópico de ${ }^{13} \mathrm{C}$, diferente da dieta na fase inicial $\left(\delta^{13} \mathrm{C}=-19,94\right.$ e $-19,93 \%$ ) . A mudança na composição da dieta objetivou provocar nova alteração no sinal isotópico para captar a velocidade na taxa de turnover da mucosa intestinal após o desafio. Nesta fase, portanto, aves passaram a receber quatro tratamentos distintos: $\mathrm{T} 1=$ controle, sem suplementação com nucleotídeos, $\mathrm{T} 2=$ dieta suplementada com $0,07 \%$ de nucleotídeos, $\mathrm{T} 3=\mathrm{T} 1$ mais desafio de coccidiose e $\mathrm{T} 4=\mathrm{T} 2$ mais desafio de coccidiose. Todas as rações eram isentas de antibióticos melhoradores de desempenho, anticoccidianos e ingredientes de origem animal. As composições das rações experimentais e seus valores isotópicos estão apresentados na tabela 1.

Foram colhidas amostras de mucosa aos 21; $22 ; 23 ; 26 ; 28 ; 35 ; 42$ dias de idade, procedendo-se do mesmo modo descrito para a fase anterior. Também, nessas idades, foram avaliados os escores de lesão na mucosa intestinal de acordo com a metodologia de JOHNSON \& REID (1970) para fornecer classificação numérica de lesões macroscópicas causadas por coccídios.

Para realização das análises isotópicas da mucosa intestinal, as amostras foram descongeladas e pesadas em cápsulas de estanho, aproximadamente $300 \mu \mathrm{g}$ de amostras para determinação das razões isotópicas do carbono. As cápsulas foram introduzidas no espectrômetro de massa DELTA-S (Finnigan Mat) acoplado ao Analisador Elementar (EA 1108 CHN) da UNESP - Botucatu - IB - Centro de Isótopos Estáveis. As amostras foram queimadas quantitativamente para obtenção de $\mathrm{CO}_{2}$.

Os resultados foram expressos em notação $\delta^{13} \mathrm{C}$, em relação ao padrão Peedee Belemnite (PDB), com erro de análise da ordem de $0,2 \%$ o e calculado pela equação $\delta^{13} \mathrm{C}_{(\text {amostra, padrão) }}=\left[\left(\mathrm{R}_{\text {amostra }} / \mathrm{R}_{\text {padrão }}\right)-1\right] \times 10^{3}$, em que $\delta^{13} \mathrm{C}=$ enriquecimento relativo da razão ${ }^{13} \mathrm{C} /{ }^{12} \mathrm{C}$ da amostra em relação ao padrão PDB (adimensional) e $\mathrm{R}=$ razão isotópica $\left({ }^{13} \mathrm{C} /{ }^{12} \mathrm{C}\right)$ da amostra e do padrão (adimensional).

Os dados isotópicos obtidos foram compilados em curva isotópica padrão com o auxílio do software Origin ${ }^{\circledR}$ 6.0 Professional (Microcal Software, 1999) e serviram para mensurar quantitativamente a velocidade de substituição do carbono das dietas na mucosa intestinal depois de determinado intervalo de tempo. Para isso, foi empregada a função exponencial do tempo expressa pela equação $\delta^{13} \mathrm{C}(\mathrm{t})=\delta^{13} \mathrm{C}(\mathrm{f})+\left[\delta^{13} \mathrm{C}\right.$ (i) $-\delta^{13} \mathrm{C}(\mathrm{f}) \mathrm{e}^{\mathrm{e}}$, em que $\delta^{13} \mathrm{C}(\mathrm{t})=$ enriquecimento isotópico do tecido em qualquer tempo (t) (adimensional); $\delta^{13} \mathrm{C}(\mathrm{f})$ = enriquecimento isotópico do tecido no patamar de equilíbrio, ou condição final (adimensional); $\delta^{13} \mathrm{C}(\mathrm{i})=$ enriquecimento isotópico do tecido, na condição inicial (adimensional); $\mathrm{k}=$ constante de troca (turnover) em unidades de tempo ${ }^{-1}$ e $\mathrm{t}=$ tempo (em dias) desde a substituição da ração (DUCATTI et al., 2002).

O tempo necessário para que ocorra a substituição total dos átomos iniciais pelos átomos finais $\left(\mathrm{T}_{99,99 \%}\right)$ pode ser determinado pela equação $\mathrm{T}_{99,99 \%}=-1 / \mathrm{k} \ln (1-\mathrm{f}$ ), na qual o valor de $\mathrm{f}$ (átomos trocados) pode variar de zero (0) a 0,9999 . A meia-vida $\left(\mathrm{T}_{50 \%}\right)$ do ${ }^{13} \mathrm{C}$ na mucosa intestinal na condição de substituição dos $50 \%$ dos átomos trocados pode ser mensurada pela equação $\mathrm{T}_{50 \%}=\ln 2 / \mathrm{k} \operatorname{com~} \mathrm{f}=0,5$ em que $\mathrm{T}_{50 \%}=$ meia-vida, unidade: tempo (dias); $\ln =\log$ aritmo niperiano; $\mathrm{k}=$ constante do turnover, unidade: tempo ${ }^{-1}$, fornecendo uma ideia de velocidade no processo de troca dos isótopos estáveis nos tecidos (DUCATTI et al., 2002).

\section{RESULTADOS E DISCUSSÃO}

Na figura 1a, estão apresentados os valores isotópicos de $\delta^{13} \mathrm{C}$ da mucosa intestinal das aves de 1 a 21 dias de idade, as quais receberam dietas compostas predominantemente por plantas do ciclo fotossintético $\mathrm{C}_{3}$, suplementadas ou não com nucleotídeos. A análise dos resultados de $\delta^{13} \mathrm{C}$ da mucosa intestinal, de 1 a 21 dias de idade, do grupo que recebeu dieta sem adição de nucleotídeos resultou na equação $\delta^{13} \mathrm{C}=-26,92+7,47$ $\mathrm{e}^{-0,6567 \mathrm{t}}\left(\mathrm{R}^{2}=0,98\right)$ com meia-vida do carbono calculada de 1,06 dias ou troca total em 10,5 dias. Para os animais que receberam dieta com adição de nucleotídeos, a equação obtida foi: $\delta^{13} \mathrm{C}=-27,14+7,53 \mathrm{e}^{-0,6852 t}\left(\mathrm{R}^{2}=0,99\right)$ com meia-vida do carbono de 1,01 dias ou troca total em 10,1 dias para o mesmo período. Verifica-se que o valor-meia vida encontrado foi menor para os animais que receberam dieta suplementada, indicando que a suplementação com nucleotídeos propicia aceleração 
Tabela 1 - Composição e valores nutricionais calculados das rações.

\begin{tabular}{|c|c|c|c|c|}
\hline \multirow{4}{*}{ Ingredientes(\%) } & \multicolumn{4}{|c|}{-Níveis de inclusão de nucleotídeos-- } \\
\hline & \multicolumn{2}{|c|}{1 a 21 dias de idade } & \multicolumn{2}{|c|}{22 a 42 dias de idade } \\
\hline & \multicolumn{2}{|c|}{ (Predominantemente $\mathrm{C}_{3}$ ) } & \multicolumn{2}{|c|}{ (Predominantemente $\mathrm{C}_{4}$ ) } \\
\hline & $0,00 \%$ & $0,07 \%$ & $0,00 \%$ & $0,07 \%$ \\
\hline Quirera de arroz & 58,415 & 58,415 & - & - \\
\hline Milho & - & - & 61,844 & 61,844 \\
\hline AccelerAid $^{\circledR 1}$ & 0,000 & 0,300 & 0,000 & 0,300 \\
\hline Farelo de soja & 34,425 & 34,425 & 30,928 & 30,928 \\
\hline Óleo de soja & 3,095 & 3,095 & 3,343 & 3,343 \\
\hline $\mathrm{NaCl}$ & 0,500 & 0,500 & 0,480 & 0,480 \\
\hline Suplemento vitamínico ${ }^{2}$ & 0,100 & 0,100 & 0,100 & 0,100 \\
\hline Suplemento mineral ${ }^{3}$ & 0,050 & 0,050 & 0,050 & 0,050 \\
\hline Calcário calcítico & 0,810 & 0,810 & 0,830 & 0,830 \\
\hline Fosfato bicálcico & 1,900 & 1,900 & 1,670 & 1,670 \\
\hline DL-metionina & 0,155 & 0,155 & 0,175 & 0,175 \\
\hline L-lisina & 0,190 & 0,190 & 0,230 & 0,230 \\
\hline Cloreto de colina ${ }^{4}$ & 0,060 & 0,060 & 0,050 & 0,050 \\
\hline Caulim $^{5}$ & 0,300 & 0,000 & 0,300 & 0,000 \\
\hline Energia metabolizável (kcal/kg) & 3000 & $\begin{array}{l}\text { dos---- } \\
3000\end{array}$ & 3100 & 3100 \\
\hline Proteína bruta (\%) & 20,79 & 20,79 & 19,41 & 19,41 \\
\hline Cálcio (\%) & 0,89 & 0,89 & 0,83 & 0,83 \\
\hline Fósforo disponível (\%) & 0,44 & 0,44 & 0,41 & 0,41 \\
\hline Metionina (\%) & 0,50 & 0,50 & 0,48 & 0,48 \\
\hline Aminoácidos sulfurados (\%) & 0,81 & 0,81 & 0,79 & 0,79 \\
\hline Lisina $(\%)$ & 1,27 & 1,27 & 1,19 & 1,19 \\
\hline Potássio (\%) & 0,74 & 0,74 & 0,74 & 0,74 \\
\hline Sódio (\%) & 0,22 & 0,22 & 0,21 & 0,21 \\
\hline Cloro (\%) & 0,34 & 0,34 & 0,33 & 0,33 \\
\hline Ácido linoléico (\%) & 2,10 & 2,10 & 3,14 & 3,14 \\
\hline Valor isotópico em $\delta^{13} \mathrm{C}(\% \circ)^{6}$ & $\begin{array}{l}-----V a \\
-27,95\end{array}$ & $\begin{array}{l}\text { dos------ } \\
-27,98\end{array}$ & $-19,94$ & $-19,93$ \\
\hline
\end{tabular}

${ }^{1}$ AccelerAid ${ }^{\circledR}: 22,5 \%$ de nucleotídeos (concentrações iguais de adenina, guanina, citosina e uracila). ${ }^{2}$ Suplemento vitamínico (por kg de ração): vit. A, $15.000 \mathrm{UI}$; vit. $\mathrm{D}_{3}, 3.000 \mathrm{UI}$; vit. E, 30mg; vit. $\mathrm{K}_{3}, 4 \mathrm{mg}$; B1, 3mg; vit. B2, 6mg; vit. B6, 6mg; vit. B12, 30mcg; niacina, 40mg; ac. fólico, $1,5 \mathrm{mg}$; ác. pantotênico, $15 \mathrm{mg}$; biotina, $120 \mathrm{mcg}$; vit. C, $50 \mathrm{mg}$; antioxidante. ${ }^{3}$ Suplemento mineral (por kg de ração): selênio, 180mcg; iodo, 700mcg; ferro, 48mg; cobre, $10 \mathrm{mg}$; manganês, $78 \mathrm{mg}$; zinco, $55 \mathrm{mg}$. ${ }^{4}$ Cloreto de colina $(70 \%) .{ }^{5}$ Veículo para substituir o nucleotídeo. ${ }^{6}$ Valor isotópico expresso em $\delta^{13} \mathrm{C}$ relativo ao padrão PeeDee Belemnite (PDB).

na velocidade de troca do carbono na mucosa intestinal de frangos de corte na fase inicial de crescimento e, portanto, maior aceleração no crescimento intestinal. Esses resultados corroboram os encontrados por outros autores, demonstrando que, ao suplementar a dieta de ratos com nucleotídeos, ocorre aceleração do desenvolvimento do intestino (TSUJINAKA et al., 1993) e aumento do conteúdo de DNA da mucosa intestinal (UAUY et al., 1990), suportando a teoria de que os nucleotídeos afetam positivamente o crescimento e maturação do epitélio do intestino delgado (ORTEGA et al., 1995).

Nas figuras $1 \mathrm{~b}$ e c, são apresentados os valores isotópicos de $\delta^{13} \mathrm{C}$ da mucosa intestinal das aves dos 22 aos 42 dias de idade, quando passaram a receber dietas compostas predominantemente por plantas do ciclo fotossintético $\mathrm{C}_{4}$ e suplementadas ou não com nucleotídeos, bem como aves submetidas ou não a desafio por coccidiose.

A análise dos resultados de $\delta^{13} \mathrm{C}$ da mucosa intestinal do grupo que recebeu dieta sem adição de nucleotídeos e sem desafio resultou na expressão $\delta^{13} \mathrm{C}=-21,61-6,76 \mathrm{e}^{-0,3829(-21)}\left(\mathrm{R}^{2}=0,99\right)$, com meia-vida do carbono calculada de 1,81 dias ou troca total em 18,4 dias e, para os animais que receberam dieta com adição de nucleotídeos e sem desafio, a expressão obtida foi: $\delta^{13} \mathrm{C}=-21,37-5,90 \mathrm{e}^{-0,3849(-21)}\left(\mathrm{R}^{2}=0,98\right)$ com meia-vida do carbono de 1,80 dias ou troca total em 18 dias. Verifica- 


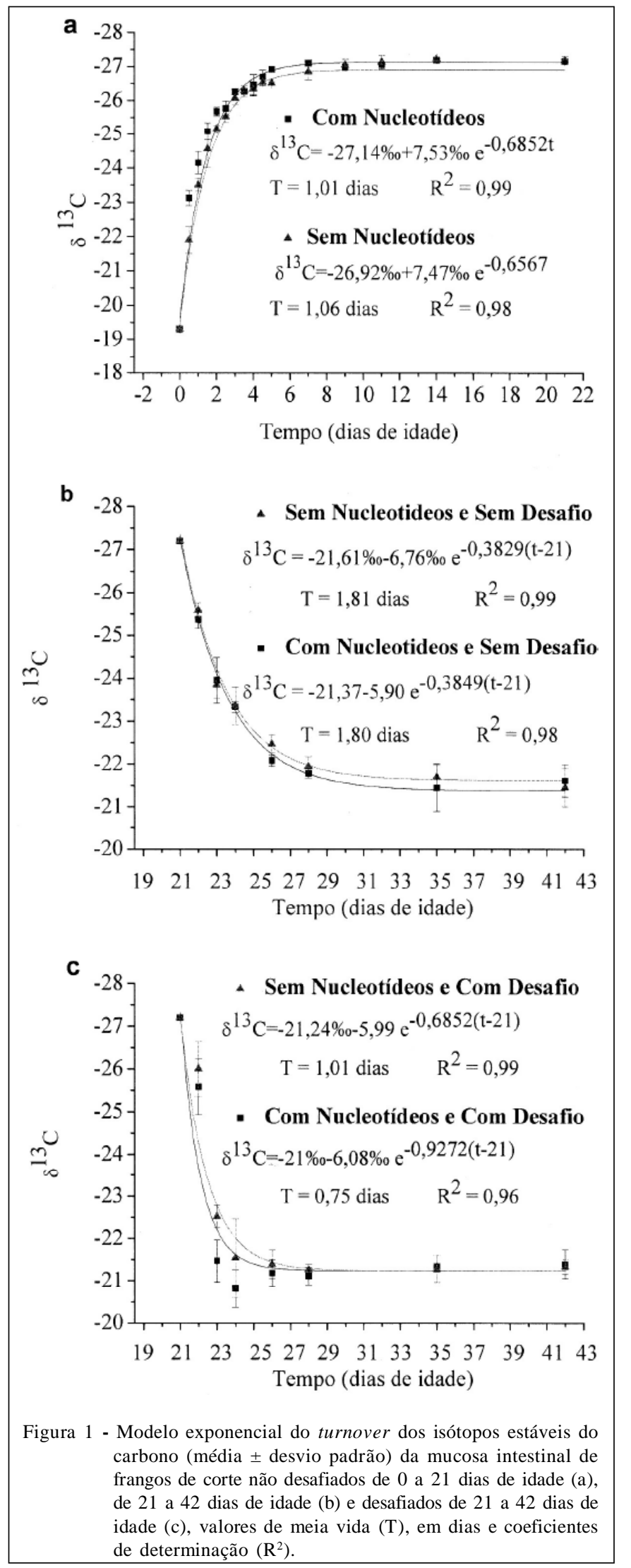

Ciência Rural, v.41, n.9, set, 2011. 
se que não houve influência da suplementação com nucleotídeos na velocidade de troca do carbono na mucosa intestinal de aves não submetidas a desafio durante a fase de 22 a 42 dias de idade. Aos 42 dias de idade, as aves já apresentam intestino maturado, explicando, portanto, porque não se pode verificar efeito dos nucleotídeos sobre o desenvolvimento intestinal como observado na fase inicial de 1 a 21 dias de idade. Porém, os resultados de $\delta^{13} \mathrm{C}$ da mucosa intestinal do grupo que recebeu dieta sem adição de nucleotídeos e com desafio resultou na expressão $\delta^{13} \mathrm{C}=-21,24-5,99 \mathrm{e}^{-0,6852(t-21)}\left(\mathrm{R}^{2}=0,99\right)$ com meia-vida do carbono calculada de 1,01dias ou troca total em 10,8 dias e, para os animais que receberam dieta com adição de nucleotídeos e com desafio, a expressão obtida foi: $\delta^{13} \mathrm{C}=-21-6,08 \mathrm{e}^{-0,9272(-21)}\left(\mathrm{R}^{2}=0,96\right)$ com meia-vida do carbono de 0,75 dias ou troca total em 7,45 dias. Comparando os dois grupos desafiados, o valor de meia-vida encontrado para o grupo que recebeu dieta sem adição de nucleotídeos foi quase $30 \%$ maior em relação àqueles que receberam dieta suplementada com nucleotídeos.

Essa diferença acentuada evidencia a influência dos nucleotídeos na velocidade de troca do carbono no tecido lesado, indicando aceleração no processo de renovação da mucosa intestinal e sua regeneração após os danos causados por patógenos. Esses resultados corroboram os encontrados por ADJEI et al. (1992) e FANSLOW et al. (1988), que observaram melhora na integridade intestinal de ratos após lesões provocadas por bactérias e fungos patogênicos ao suplementá-los com nucleotídeos por meio da dieta.
Em criatórios comerciais, as aves estão constantemente sob desafio por patógenos durante todo período de criação. O mais comum na indústria avícola, especialmente para frangos de corte, são patógenos intestinais como bactérias e Eimeria sp. que lesam a mucosa intestinal afetando a absorção dos nutrientes. Sendo assim, os nucleotídeos podem atuar sob essas condições, favorecendo a regeneração da mucosa intestinal lesada.

Na figura 2, são apresentados os dados de escores de lesão provocados por oocistos de Eimeria acervulina. Os valores médios encontrados para as aves que não estavam recebendo dieta suplementada com nucleotídeos foram $1 ; 2,3 ; 3 ; 3 ; 3,3 ; 3,3 ; 2$ e 0 nas idades de $21,22,23,24,26,28,35$ e 42 dias, respectivamente. Por outro lado, para as aves que estavam recebendo dieta suplementada com nucleotídeos, os valores encontrados foram: 1; 1,3;2,3; 2,$3 ; 2,3 ; 2 ; 0$ e 0 , respectivamente, nas mesmas idades. Verificam-se menores escores de lesão e mais rápida recuperação da mucosa intestinal de frangos recebendo dieta suplementada com nucleotídeos quando comparados com os que recebiam dieta não suplementada. Esses resultados serviram de base de comparação com a técnica isotópica utilizada para avaliar taxa de turnover da mucosa intestinal, concordando com GANNES et al. (1998) ao afirmar que dietas com assinaturas isotópicas contrastantes podem ser usadas para mensurar o turnover de componentes corporais e órgãos de animais.

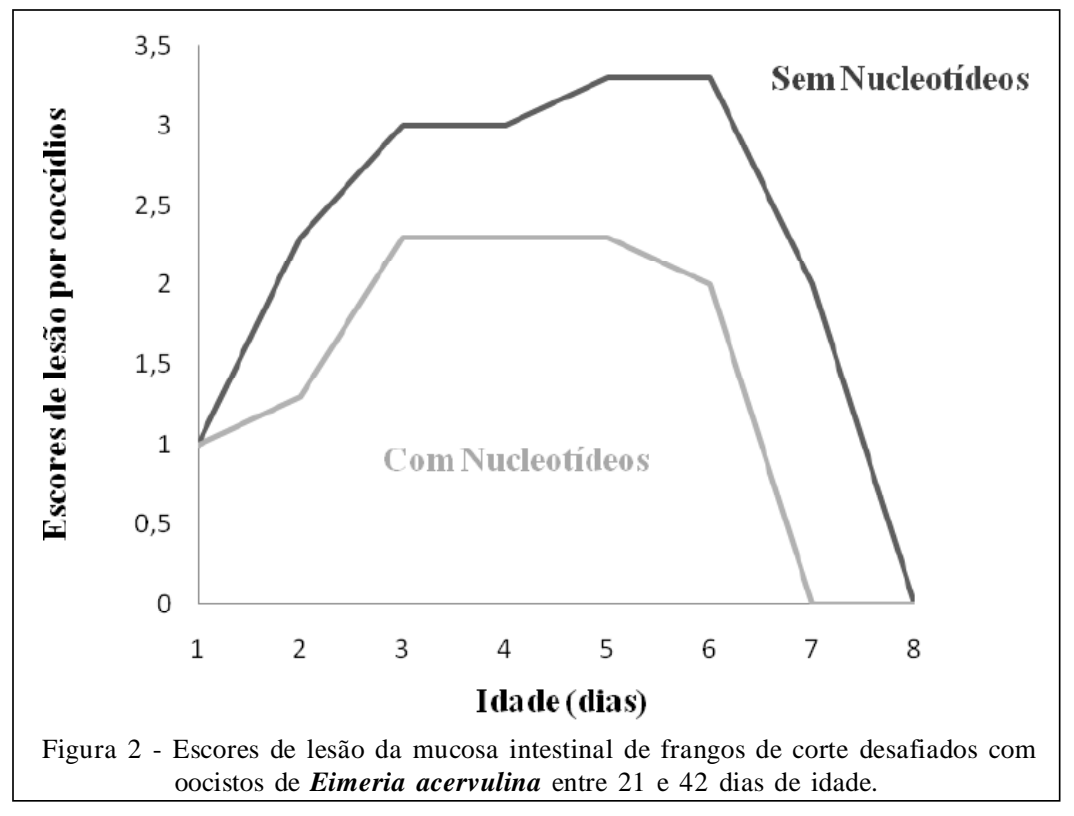

Ciência Rural, v.41, n.9, set, 2011. 


\section{CONCLUSÃO}

A suplementação com nucleotídeos na ração de frangos de corte acelera o turnover da mucosa intestinal durante o crescimento e maturação do intestino e durante regeneração desse tecido após os danos causados em sua estrutura, mostrando que nucleotídeos são importantes para a manutenção e função da mucosa intestinal.

A técnica dos isótopos estáveis ambientais mostrou-se eficiente para medir taxas de turnover na mucosa intestinal de frangos de corte.

\section{AGRADECIMENTOS}

À FAPESP - Fundação de Amparo a Pesquisa do Estado de São Paulo -, pela bolsa e auxílio concedidos.

\section{COMITÊ DE ÉTICA E BIOSSEGURANÇA}

A pesquisa foi aprovada pela Câmara de Ética em Experimentação Animal da FMVZ - UNESP, Campus de Botucatu (protocolo n.13/2006 - CEEA).

\section{REFERÊNCIAS}

ADJEI, A.A. et al. Comparative effects of dietary nucleosidenucleotide mixture and its components on endotoxin induced bacterial translocation and small intestinal injury in protein deficient mice. Gut, v.34, n.4, p.531-537, 1996. Disponível em: <http://gut.bmj.com/content/38/4/531>. Acesso em: 20 jun. 2011. doi:10.1136/gut.38.4.531.

BUENO, J. et al. Effect of dietary nucleotides on small intestinal repair after diarrhea. Histological and ultrastructural changes. Gut, v.35, p.926-933, 1994. Disponível em: <http:// gut.bmj.com/content/35/7/926.full.pdf $>$. Acesso em: 20 jun. 2011. doi:10.1136/ gut.35.7.926.

CALDARA, F.R. et al. Glutamina e turnover do carbono da mucosa intestinal de leitões desmamados. Revista Brasileira de Zootecnia, v.39, n.12, p.2664-2669, 2010. Disponível em: 〈http://www.scielo.br/pdf/rbz/v39n12/a15v39n12.pdf >. Acesso em: 20 jun. 2011. doi:10.1590/S151635982010001200015 .

CRUZ, V.C. et al. Influence of diet on assimilation and turnover of $13 \mathrm{C}$ in the tissues of broiler chickens. British Poultry Science, v.46, n.3, p.382-389, 2005. Disponível em: <http:/ / w w w. i n f o r m a w o r l d . c o m / s m p p / content $\sim \mathrm{db}=\mathrm{all} \sim \mathrm{content}=\mathrm{a} 713993000>$. Acesso em: 20 jun. 2011. doi:10.1080/0071660500126847.

DUCATTI, C. et al. Modelo teórico e experimental da reciclagem do carbono - 13 em tecidos de mamíferos e aves. Scientia Agrícola, v.59, n.1, p.29-33, 2002. Disponível em: $<$ http://www.scielo.br/scielo.php?pid=S0103$90162002000100003 \&$ script=sci_arttext $>$. Acesso em: 20 jun. 2011. doi: 10.1590/S0103-90162002000100003.

FANSLOW, W.C. et al. Effect of nucleotide restriction and supplementation on resistance to experimental murine candidiasis.
Journal Parenteral Enteral Nutrition, v.12, p.49-52, 1988. Disponível em: <http://pen.sagepub.com/content/12/1/49.short>. Acesso em: 20 jun. 2011. doi: 10.1177/014860718801200149.

GANNES, L.Z. et al. Natural abundance variations in stable isotopes and their potential uses in animal physiological ecology. Comparative Biochemistry Physiology, v.119A, n.3, p.725737, 1998. Disponível em: <http://www.sciencedirect.com/ science/article/pii/S1095643398010162>. Acesso em: 20 jun. 2011. doi:10.1016/S1095-6433(98)01016-2.

GOTTMANN, R. et al. Rastreabilidade de subprodutos de origem animal em dietas com levedura e trigo para frangos. Pesquisa Agropecuária Brasileira, v.43, p.1641-1647, 2008. Disponível em: <http://www.scielo.br/ scielo.php?pid=S0100204X2008001200001\&script=sci_arttext $>$. Acesso em 20 jun. 2011. doi: 10.1590/S0100204X2008001200001.

HOBSON, K.A.; CLARK, R.G. Assessing avian diets using stable isotopes I: Turnover of ${ }^{13} \mathrm{C}$ in tissues. Condor, v.94, p.181188, 1992. Disponível em: <http://www.sciencedirect.com/ science/article/pii/S1095643398010162>. Acesso em: 20 jun. 2011. doi:10.1016/S1095-6433(98)01016-2.

JOHNSON, J.K.; REID, W.M. Anticoccidial drugs: lesion scoring techniques in battery and floor-pen experiments with chickens. Experimental Parasitology, v.28, p.30-36, 1970. Disponível em:<http://www.sciencedirect.com/science/article/pii/ 0014489470900639>. Acesso em: 20 jun. 2011. doi:10.1016/ 0014-4894(70)90063-9.

METGES, C. et al. Dependence of the carbon isotope contents of breath carbon dioxide, milk, serum and rumen fermentation products on de delta 13C value of food in dairy caws. British Journal of Nutrition, v.63, p.187-196, 1990. Disponível em: <ht t p ://journals.cambridge.org/action/ displayAbstract?fromPage $=$ on line $\&$ aid $=865720$ $\&$ fulltType $=$ RA\&fileId=S0007114590000253 $>$. Acesso em 20 jun. 2011. doi: 10.1079/BJN1990010.

MICROCAL SOFTWARE ORIGIN ${ }^{\circledR} 6.0$ PROFESSIONAL. Origin data analysis and technical graphics. USA: Microcal Software, 1999. 1 CD.

ORTEGA, M.A. et al. Maturation status of small intestine epithelium in rats deprived of dietary nucleotides. Life Science, v.56, p.1623-1630, 1995. Disponível em: <http:// www.sciencedirect.com/science/article/pii/ 002432059500129T>. Acesso em: 20 jun. 2011. doi:10.1016/ 0024-3205(95)00129-T.

ROSTAGNO, H.S. et al. Tabelas brasileiras para aves e suínos: composição de alimentos e exigências nutricionais. Viçosa: Universidade Federal de Viçosa, 2005. 286p. Disponível em: <http://centrodepesquisasavicolas.files. wordpress.com/2011/02/ tabelas-brasileiras2005.pdf>. Acesso em 20 jun. 2011.

TSUJINAKA, T. et al. Role of nucleoside and nucleotide misture in intestinal mucosal growth under total parenteral nutrition. Nutrition, v.9, p.532-535, 1993. Disponível em: <http:// www.ncbi.nlm.nih.gov/pubmed/8111144>. Acesso em: 20 jun. 2011.

UAUY, R. et al. Effect of dietary nucleosides on growth and maturation of the developing gut in the rat. Journal Pediatry 
Gastroenterology Nutrition, v.10, p.497-503, 1990. Disponível em: <http://www.cabdirect.org/abstracts/ 19911433929.html?freeview=true>. Acesso em: 20 jun. 2011. doi: 10.1097/00005176-199005000-00014.

WILLIAMS, R.B. Quantification of the crowding effect during infections with the seven Eimeria species of the domesticated fowl: its importance for experimental designs and the production of oocyst stocks. International Journal for Parasitology, v.31, p.1056-1069, 2001. Disponível em: <http:// www.sciencedirect.com/science/article/pii/ S0020751901002351>. Acesso em: 20 jun. 2011. doi:10.1016/ S0020-7519(01)00235-1.
YAMAUCHI, K. et al. A nucleoside-nucleotide mixture and its components increase lymphoproliferative and delayed hypersensitivity responses in mice. Journal of Nutrition, v.126, p.1571-1577, 1996. Disponível em: <http:// www.ncbi.nlm.nih.gov/pubmed/8648430>. Acesso em: 20 jun. 2011.

YU, I.T. et al. Roles of glutamine and nucleotides in combination in growth, immune responses and FMD antibody titles of weaned pigs. Animal Science, v.75, p.379-385, 2002. Disponível em: <http://www.bsas.org.uk/Publications/ Animal_Science/2002/Volume_75_Part_3/379/>. Acesso em: 20 jun. 2011. 